\title{
Remaking the Engineering Building: Facility Design Best Practices
}

\section{Mr. Christopher Purdy, SmithGroupJJR}

Chris Purdy is the Higher Education Practice Director for SmithGroupJJR. With twenty five years of experience focusing on facilities for higher education, he understands the unique requirements of campus architecture including longevity, sensitivity to context, sustainability and student engagement. Chris has special expertise in providing leadership for projects that focus on student STEM education and research. Some of his most notable clients include Michigan State University, Oakland University, Boston University, University of Cincinnati, Western Michigan University, University of Michigan, and University of Detroit-Mercy. Chris graduated from University of Michigan with a Bachelor of Science in Architecture degree and from University of California, Berkeley with a Master of Architecture degree.

\section{Paul Urbanek FAIA, NCARB, LEED AP, SmithGroupJJR}

\section{Paul Urbanek, FAIA, NCARB, LEED AP Vice President, Director of Design SmithGroupJJR}

As a Director of Design for SmithGroupJJR, Paul Urbanek is a highly awarded, highly recognized design professional with over 30 years of experience in architectural design for a wide range of projects. As design leader, he is directly responsible for the successful implementation of the clients design vision. Paul's creative problem solving process provides fresh viewpoints and new concepts for functionally appropriate, aesthetically exciting design solutions. His expertise extends to projects that focus on student STEM education and research including Oakland University Engineering Center, Texas Tech University Health Sciences Center, and Michigan State University Plant Sciences. As a practitioner within a large multidisciplinary design firm, Paul is a designer who understands the interrelationships between building and art. 


\section{Remaking the}

\section{Engineering Building:}

\section{Facility Design Best Practices}

\section{Introduction}

Over the last five to ten years, a shift has taken place within engineering schools nationwide toward greater engagement of students through experiential, hands-on learning opportunities. This evolution began with the move of intensive experimental and project-based labwork from the postgraduate to undergraduate level. Now, there is a strong interest in introducing hands-on learning - including opportunities to collaborate with professors and postdoctoral students on new research — during a student's first year.

For many underclassmen this change has meant the welcome injection of lab and project work into a curriculum traditionally given over to didactic math and science prerequisites. It has led to growing contact and collaboration among underclassmen and industry representatives for career mentoring, original research, and internship/employment opportunities. This has better prepared students for upper-level coursework and, eventually, entering the workforce.

As a result, for many engineering departments the shift has also become a key factor in undergraduate student recruitment and retention within a competitive field experiencing significant, sustained growth. ${ }^{1}$

This evolution has important implications for facility design. It could be said to come with its own architecture, significantly influencing not just which features and capabilities are included in a facility, but also where and how. Physical space can play an active role in fostering large-scale or long-term change, even as universities and engineering departments themselves remain primarily concerned with how design directly impacts their teaching and interactions with students.

As architects, engineers, and planners for more than a dozen collegiate engineering-department buildings in the past decade, SmithGroupJJR has helped develop a series of best practices related to facility design in this new era. While not the only firm to explore them, SmithGroupJJR has organized these new best practices into five distinct trends that encourage active participation, collaboration, and even spontaneity, reflecting an underlying ethic of student engagement from the freshman level up. We present them here, provide real-world examples from SmithGroupJJR's portfolio, and also propose methods of assessing their performance. Together, these trends provide a blueprint for using physical space to meet student demand and department priorities while accommodating future growth. 


\section{The Five Trends}

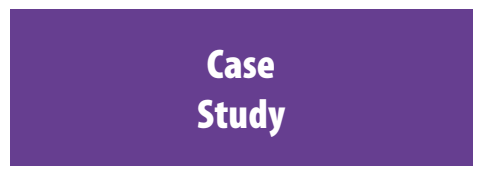

Building as

Educational Tool
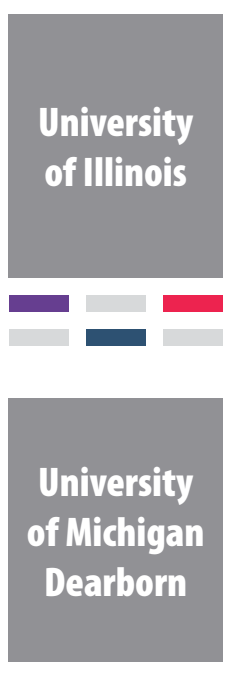

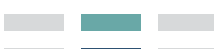
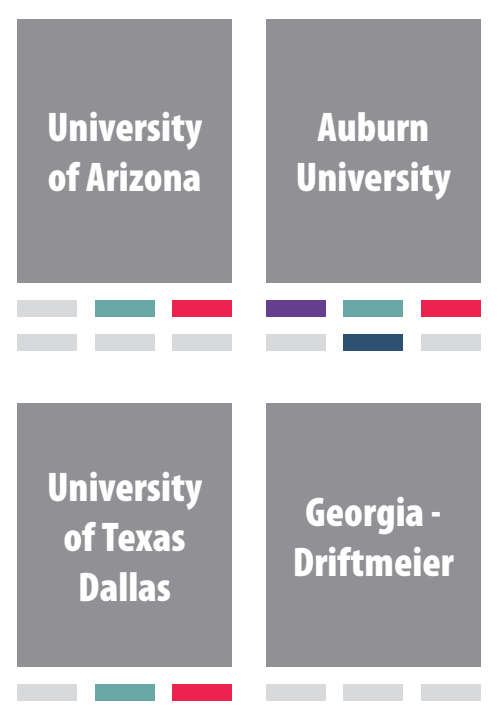

Innovation

Space
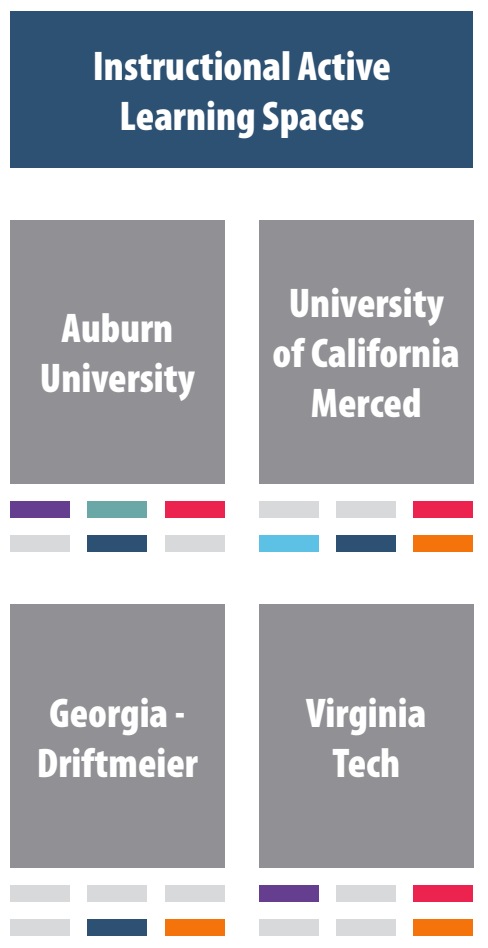
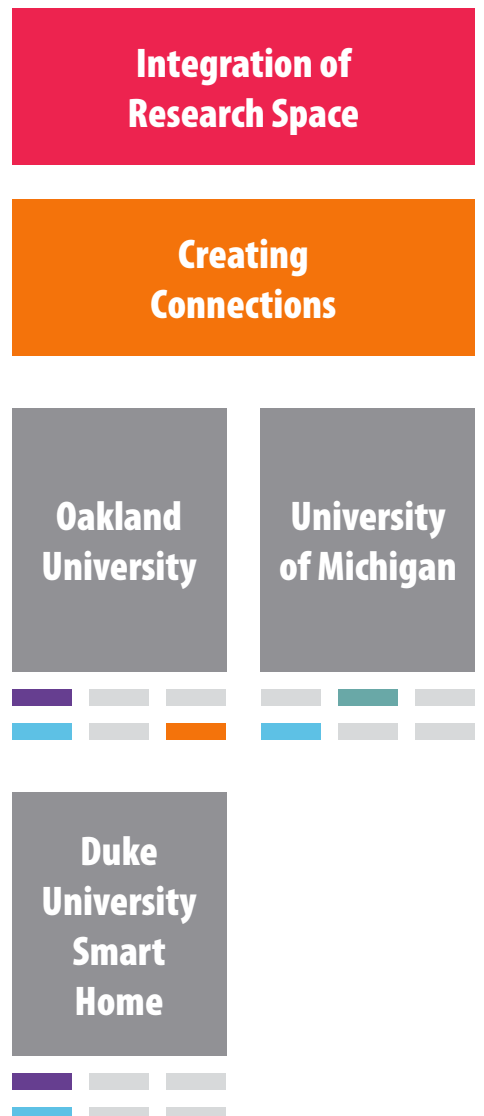

\section{Innovation Space: Industry Partners Collaboration}

The first of the five trends we have termed "innovation space." This refers to facilities, often with labs or "maker spaces" at their heart that encourage projectbased entrepreneurship and research. Such spaces foster innovation and problemsolving, providing ample room for the full development of products or ideas. They allow students to learn, research, and network with faculty and business leaders from different disciplines and programs. And they encourage collaboration and experiential learning for under- and upperclassmen alike.

Innovation spaces thus foster entrepreneurship among students in two ways: by allowing them to begin to envision themselves as practicing engineers - and gain the required skills that will help them get there - and also by helping them engage directly with community business leaders. Project-based maker spaces that enable students to take initiative and test or develop new concepts, perhaps with an industry mentor, are oriented within a broader facility design that is open and inviting.

Hallmarks of innovation spaces include: transparency and flexibility of layout; double-height or "high bay" facilities designed to provide sufficient project space; 


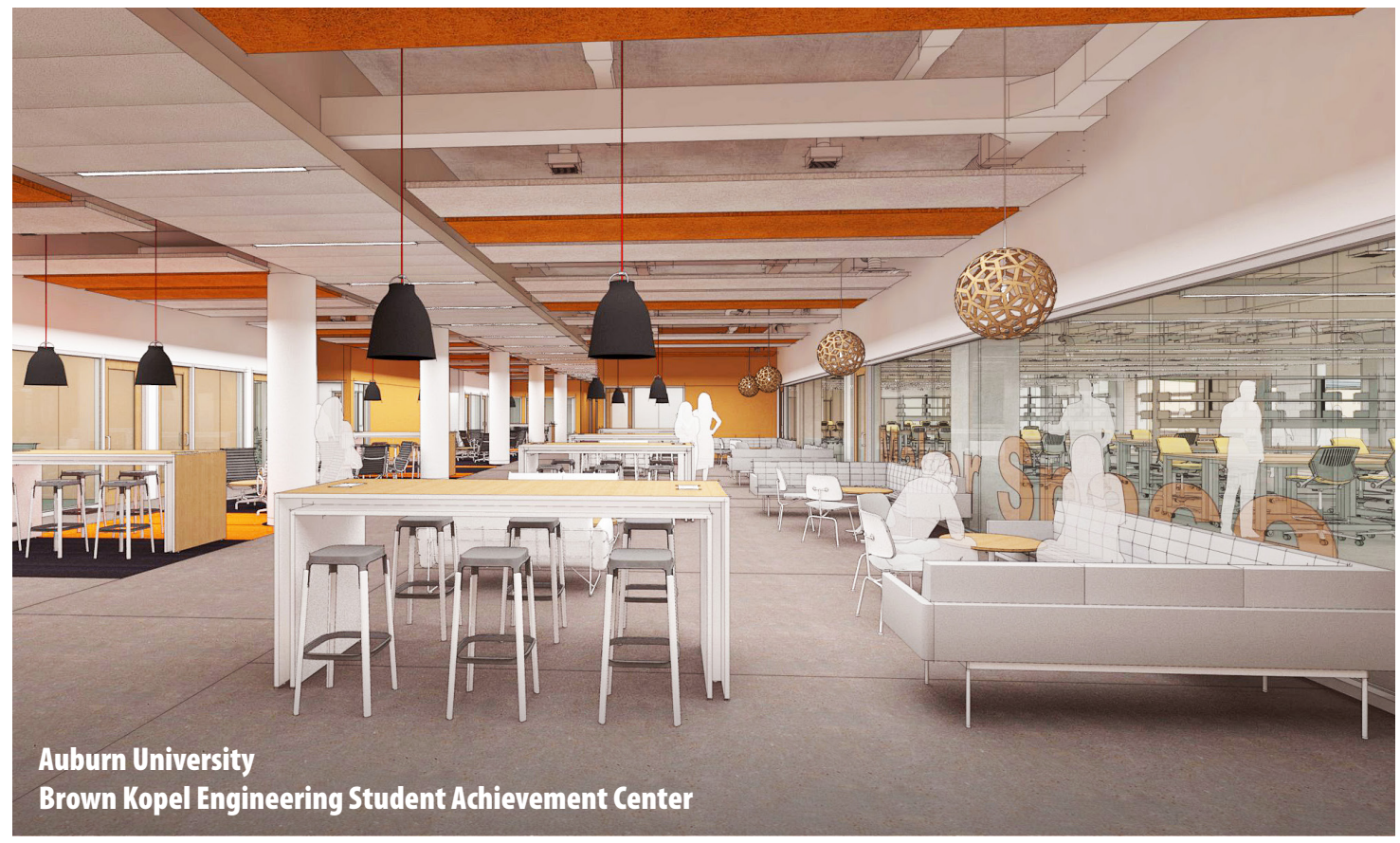

student access to a full gamut of utilities including power, data, various gases, and exhaust; easy indoor-outdoor flow to facilitate work on mobile projects like cars and helicopters; and high visibility including windows from corridors and other public areas.

At Auburn University in Alabama, SmithGroupJJR designed a 90,000-square-foot facility exemplifying these concepts. When complete later this year it will become the public face and a central resource for the Samuel Ginn College of Engineering. ${ }^{2}$ Notably, the building is also designed to serve as the home base for first-year engineering students, complete with maker spaces, fabrication labs, informal spaces, and classrooms for hands-on and problem-based learning.

Beyond this suite of hands-on educational amenities, the building's design supports innovation and engagement beginning at the freshman level through centers dedicated to tutoring and academic advising, career development, and industry collaboration, all facing the main entry and located immediately off the building's spacious doubleheight atrium.

Labs, machine shops, and other project workspaces, meanwhile, are clustered one floor down, promoting an engaging "garage" atmosphere and encouraging collaboration through proximity.

Success of innovation spaces should be defined in terms of industry collaboration, as measured via university data on industry partner visits to the department/facility or industry funding of student projects and student/faculty research. 

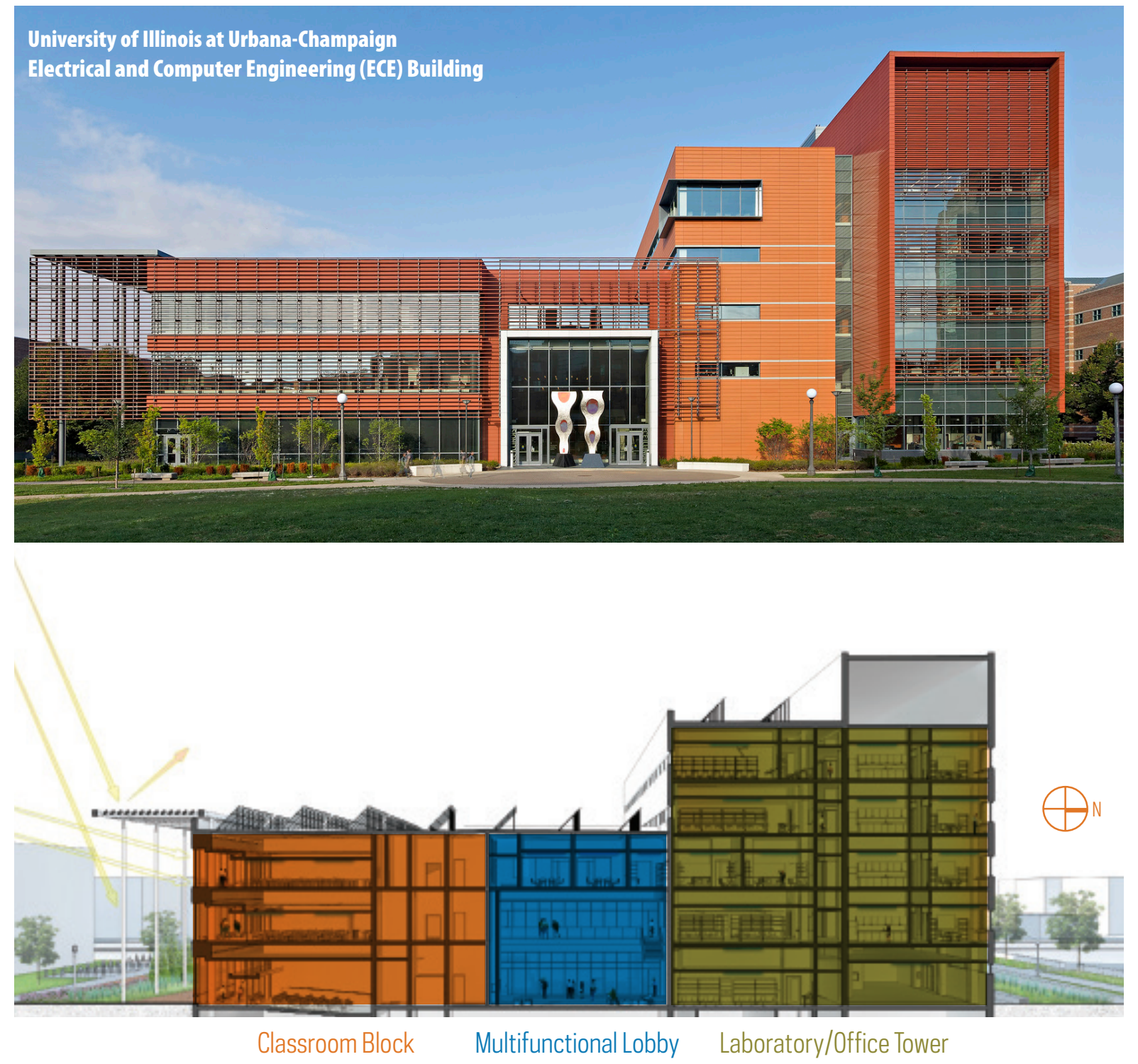

\section{Integration of Research Space}

A separate but related concept, "integration of research space" refers to incorporating research into the educational setting as a key factor in undergraduate student retention. Where innovation spaces help foster entrepreneurship and industry partnerships, research spaces play an integral and direct role in classwork. They help turn the theoretical into the physical, and allow lower-level students to translate book learning into hands-on exploration and imagination along with the opportunity to help solve real-world challenges at both local and global scales.

These spaces also encourage collaboration among students and faculty and help break down barriers both within the hierarchy of a single field and across engineering disciplines. For faculty, they also accommodate a growing interest in continuing research and engaging with students in hands-on work to complement lectures and other classroom instruction. In this setting, a faculty member may serve as both professor and adviser. 
In terms of specific design considerations, the key is not only to merge lab and instructional spaces but also to encourage student-faculty interaction beyond the classroom or office, and to offer underclassmen the same access to faculty previously enjoyed perhaps only by seniors. Faculty offices may be located closer to labs, instead of sequestered in another part of the building. Graduate-student offices may also be located nearby, allowing paths to cross freely among undergraduates, graduates, and faculty, even as traditional academic delineations remain intact.

At the University of Illinois at Urbana-Champaign, SmithGroupJJR designed the 230,000-square-foot Electrical and Computer Engineering (ECE) Building, named R\&D Magazine's 2016 Laboratory of the Year. ${ }^{3}$ The net-zero-ready facility has earned attention for its sustainability features, yet its success also hinges on design elements that draw explicit links between research and learning, and students and faculty.

Most notably, the building's five-story interdisciplinary lab and research tower - with some of the most advanced facilities dedicated to undergraduates anywhere in the nation - also includes private and group offices at two corners of the building. Fusing instructional labs, research labs, offices, and informal learning spaces in a single structure enables chance intellectual collisions among undergraduates, grad students, and faculty in various fields.

Finally, measuring the performance or success of research spaces in engineering buildings can be as simple as comparing research grant revenues before and after construction; using university data or classroom/facility surveys to track the number of students participating in research; or, over an even longer term, tracking studentresearch success via awards and real-world impacts.

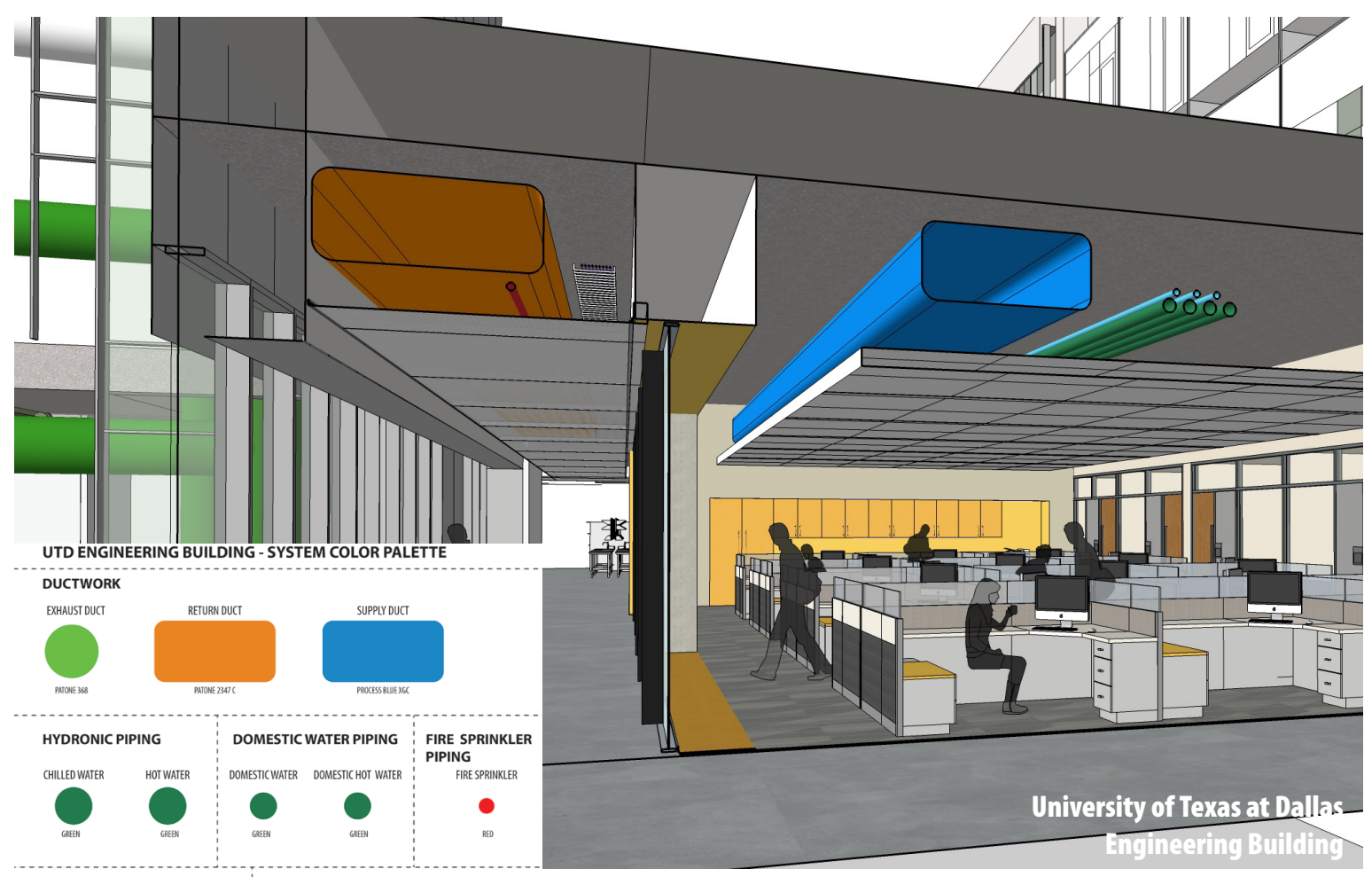




\section{Building as an Educational Tool}

A third emerging trend in engineering-school design is the use of the building itself as an educational tool. In this sense, building design and function are one and the same: the facility itself - as opposed to activities and interactions happening within it - serves the end goals of student engagement and hands-on learning at all levels. The building becomes a manifestation of the ideals expressed through individual elements such as hands-on labs, accessible faculty offices, and informal meeting spaces.

A building can serve as an educational tool in many ways, from literal transparency and views into maker spaces, to the outward and deliberate expression and celebration of core building systems such as HVAC distribution systems, plumbing and electrical conduit, which the University of Texas at Dallas Engineering Building diagram illustrates below. What these design elements have in common is the overall expression of architecture lending itself toward inspiration for discovery and invention.

Large windows and walls of glass for appropriate spaces, for example, help promote student and faculty research. They can create a sort of ripple or spillover effect where learning and discovery happening within a lab can extend beyond its walls in real time. This may
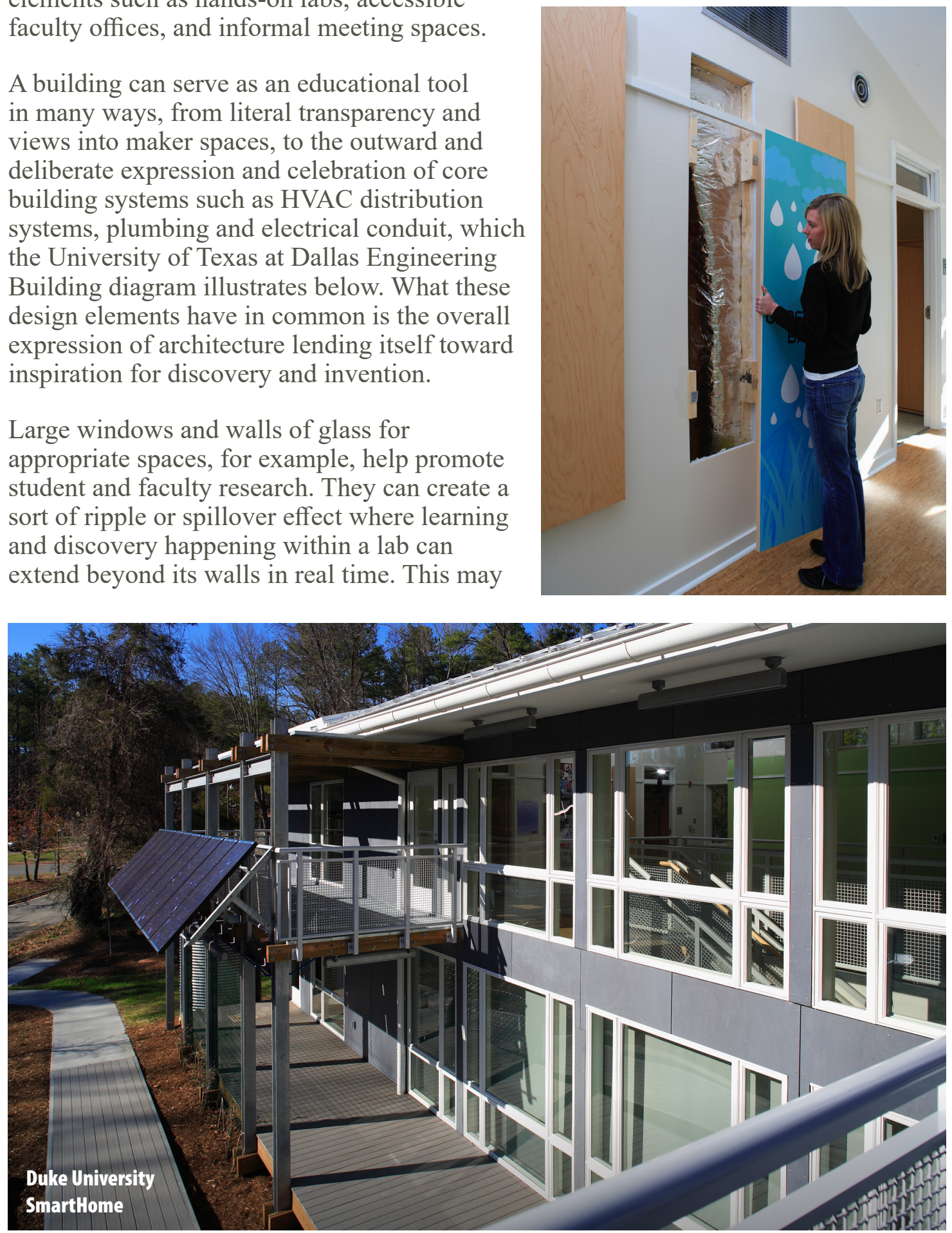
also arouse the interest of prospective or non-engineering students, thus supporting department recruitment and the field's continued advancement.

By the same token, exposed building systems can inform and inspire students, particularly those new to engineering, in direct and indirect ways. Engineering is about the integration of systems, and putting structural and utility systems on display in an educational facility provides a concrete connection to this principal.

A unique example can be found at Duke University, where in late 2007 a live-in laboratory called the SmartHome opened its doors. ${ }^{4}$ Just ten students make their home in this 6,000-square-foot LEED Platinum building, but many more - plus members of the local community - routinely visit for research and tours on sustainable design.

Students can view all of the building's systems via exposed infrastructure and removable panels, then modify them to perform experiments or upgrades. Countless novel research projects and innovations have resulted over the years, including the Photovoltaic Performance Indicator developed by four students to track solar cell output in a web-based utility granting even beginners the ability to monitor their home's solar power input. ${ }^{5}$

Because the use of a building as an educational tool is broadly defined and potentially beneficial in a wide range of ways, success metrics can also run the gamut from student retention, measured via the proportion of returning students; to student engagement, measured in a variety of ways including participation in student organizations; to recruitment and competitive advantage, measured via student application and enrollment rates.

\section{Instructional Spaces that Foster Active Learning}

Hands-on learning needn't be restricted to a lab or workshop. Modern engineering schools, and a wide range of academic disciplines across higher education, increasingly recognize the value of instructional spaces that foster interactivity. The traditional one-way flow of classroom instruction, particularly in lower-level science and math prerequisites, is evolving toward a more dynamic framework.

In an engineering building, this means allowing students to experience the power of making something in a range of different settings and environments - from 300seat lecture halls to 30 -seat multipurpose rooms - that may encourage the expression of different sorts of creativity and problemsolving.

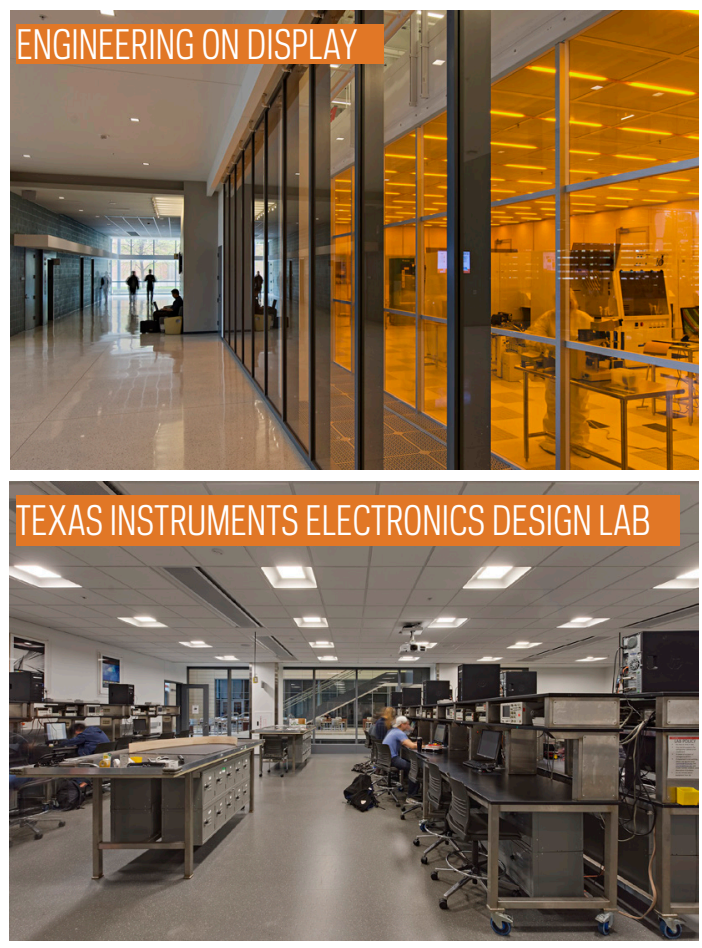


So-called "active-learning classrooms" and "instructional labs" allow students to interact with one another in small or large groups, making use of integrated technology to develop and present work while taking control of their own learning. These spaces may feature dynamic floorplans or aisle designs to make movement easier not only for students but also faculty, allowing them to walk freely through the room as needed.

Finally, integrating such innovative design considerations into sacred classroom space within a new engineering facility also ensures a holistic approach where every component, including lobbies and hallways, labs and workshops, and offices and classrooms express a unified vision around student engagement and active learning.

Indeed, instructional labs at the University of Illinois' Electrical and Computer Engineering Building are not just an add-on, but central to the top-ranked ${ }^{6}$ department's new home. While the building's classroom block contains traditional classrooms and a 400-seat auditorium, the boundary-breaking laboratory and office tower includes a range of instructional spaces of its own, all designed to teach students through hands-on activities and projects. Interactive classrooms of various sizes, 30,000 square feet of instructional labs, and an instructional clean room are located alongside one another — and faculty offices and labs — on all five floors. ${ }^{7}$

The performance of active-learning instructional spaces may be assessed via student retention, since hands-on learning is a major current driver of undergraduate student demand; or via student collaboration in clubs and study groups, since interactivity and active learning are likely to spill beyond the classroom walls.

\section{Creating Connections}

Engineering may be a discrete academic field, but the practice of its various specializations, from mechanical and civil to environmental and nuclear, often involves direct interaction with other fields. Our fifth best practice for engineering facility design thus emphasizes the importance of interdisciplinary work at all levels of undergraduate education.

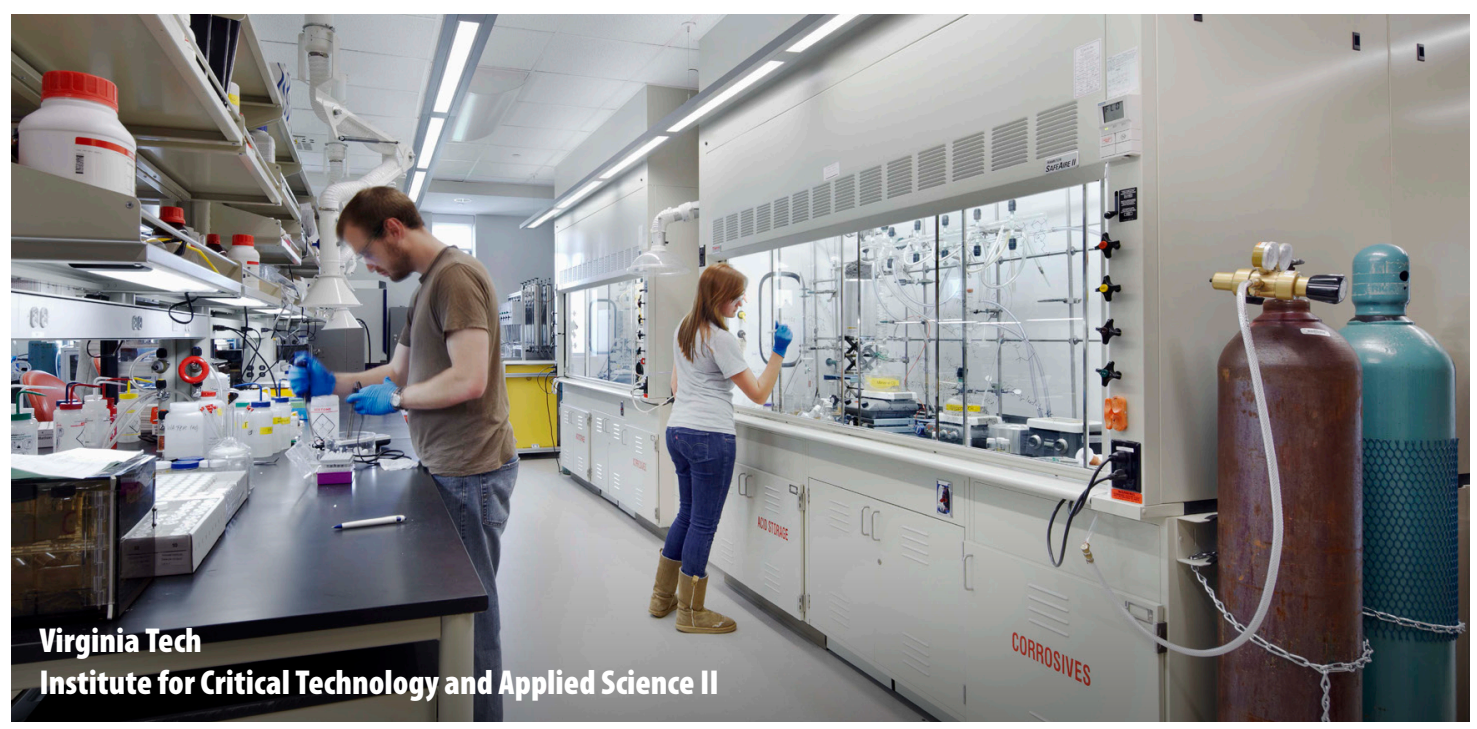


Imagine a capital ' $\mathrm{T}$ ' as a visual representation of this concept. The vertical line represents disciplinary specialization and the deep understanding of a system. The horizontal line, meanwhile, represents collaboration across a variety of systems, disciplines, and diverse individuals.

More and more, both are being viewed as valuable within engineering education, and accordingly the philosophy has even earned a name. "T-shaped" students and professionals are characterized by thorough disciplinary knowledge, an understanding of the nature of systems, and their ability to adapt and innovate across boundaries and between disciplines to address complex problems. ${ }^{8}$

Architecture can express this ideal through designs that encourage collaboration rather than separation, and that build community rather than disciplinary silos within both academia and industry. Generally, this entails organizing a building by function rather than department. In other words, rooms and other elements - labs and workshops, classrooms, student-organization offices, informal spaces, etc. - should be thought of in terms of whether they allow students, no matter their focus within engineering, to develop boundary-spanning abilities like experimenting, writing, speaking, and collaborating. Then they should be connected in a way that maximizes these functions.

At Virginia Polytechnic Institute and State University, commonly known as Virginia Tech, the SmithGroupJJR-designed Institute for Critical Technology and Applied Science II is organized expressly around the concept of interdisciplinary research. The 42,189-square-foot building completed in 2010 includes state-of-the-art laboratories and auxiliary spaces that support both applied and fundamental research.

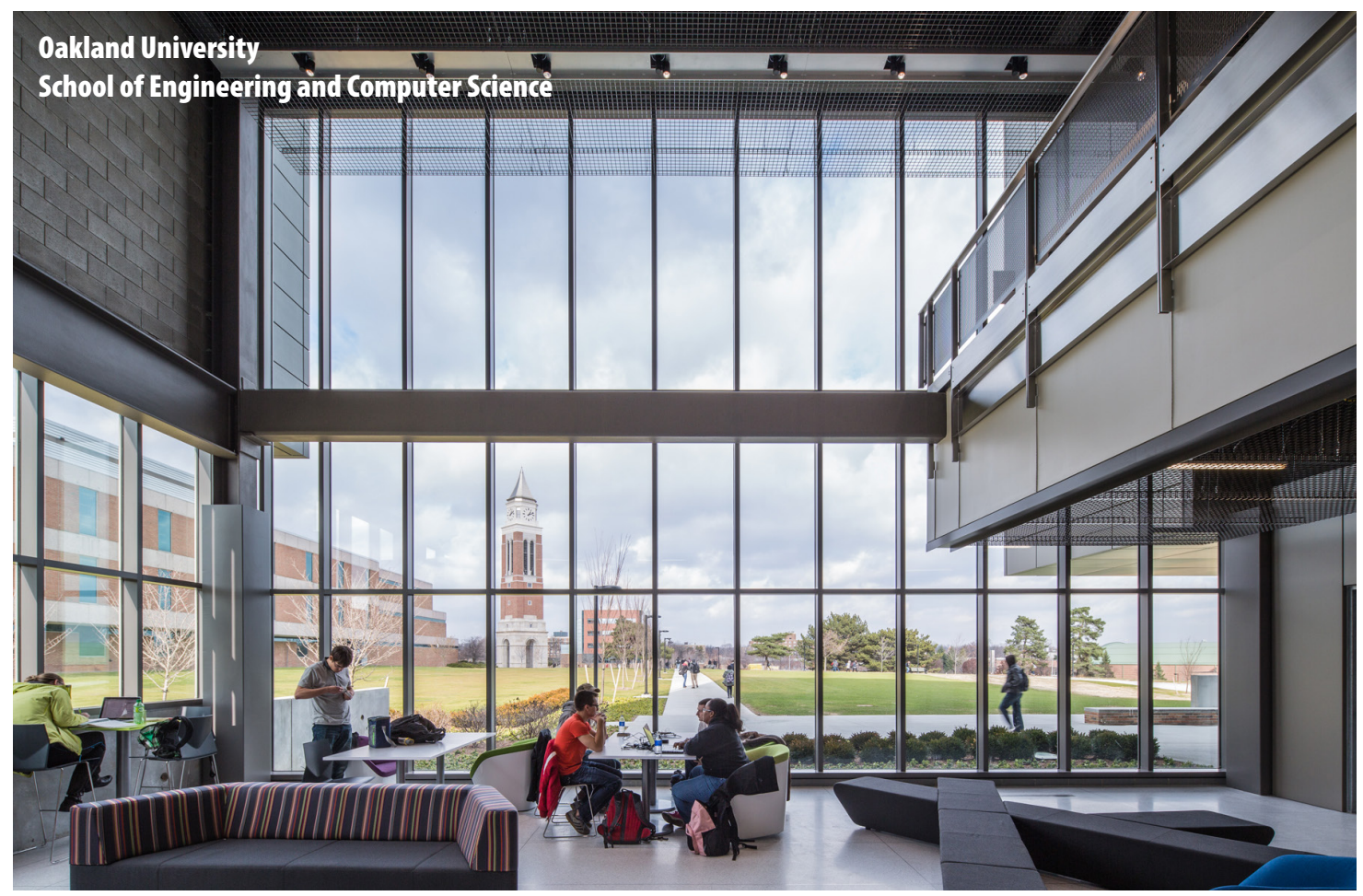


Organizing by research function - including lab capabilities, utility access, bench layout, etc. - allows the building to remain, in a sense, specialty-agnostic, and open to interdisciplinary work in fields that by their nature involve collaboration, such as bioengineering, nanotechnology, communications technology, and sensor technology.

To measure the performance of T-shaped (metaphorically speaking), connectionbuilding spaces, one could look to student success in the workplace. Specific metrics could include employer feedback on workplace readiness - collected through surveys of top employers over a period of years - or starting salaries of recent graduates, which are typically tracked by universities themselves.

\section{Case Study: Oakland University}

The School of Engineering and Computer Science at Oakland University in Rochester, Michigan, is a full-complement engineering department with about 2,800 undergraduate and graduate students. ${ }^{9}$ In 2014, the school opened a new facility designed by SmithGroupJJR that embodies many of the latest trends and best practices discussed in this paper. ${ }^{10}$

The facility design has been instrumental in enabling significant growth for the School of Engineering and Computer Science. Currently, there are more engineering students on Oakland University's campus than ever before; enrollment in the School of Engineering and Computer Science has jumped from 960 to nearly 1,800 just since 2010 and has shown a 26\% increase in enrollment from 2013 to 2014.

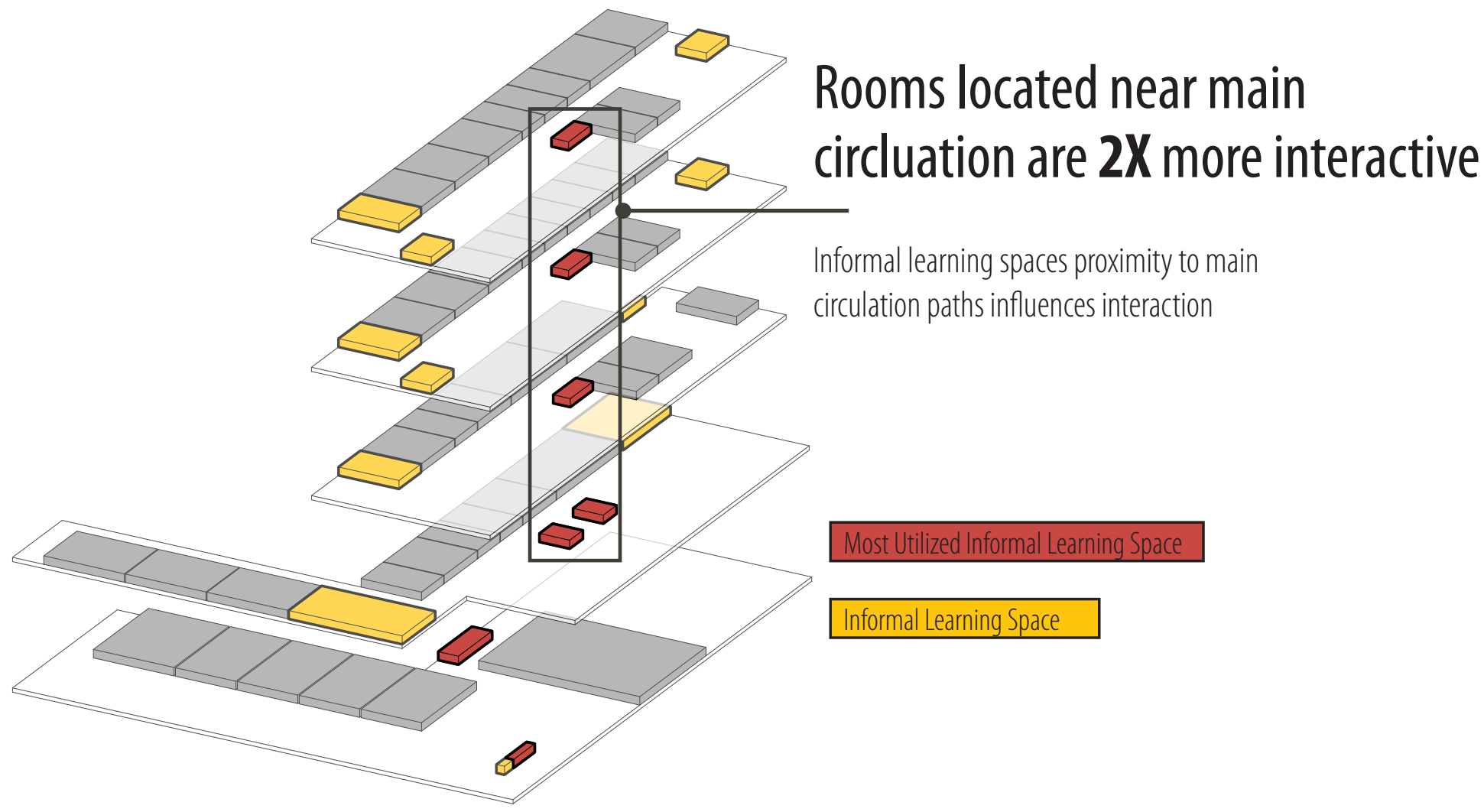



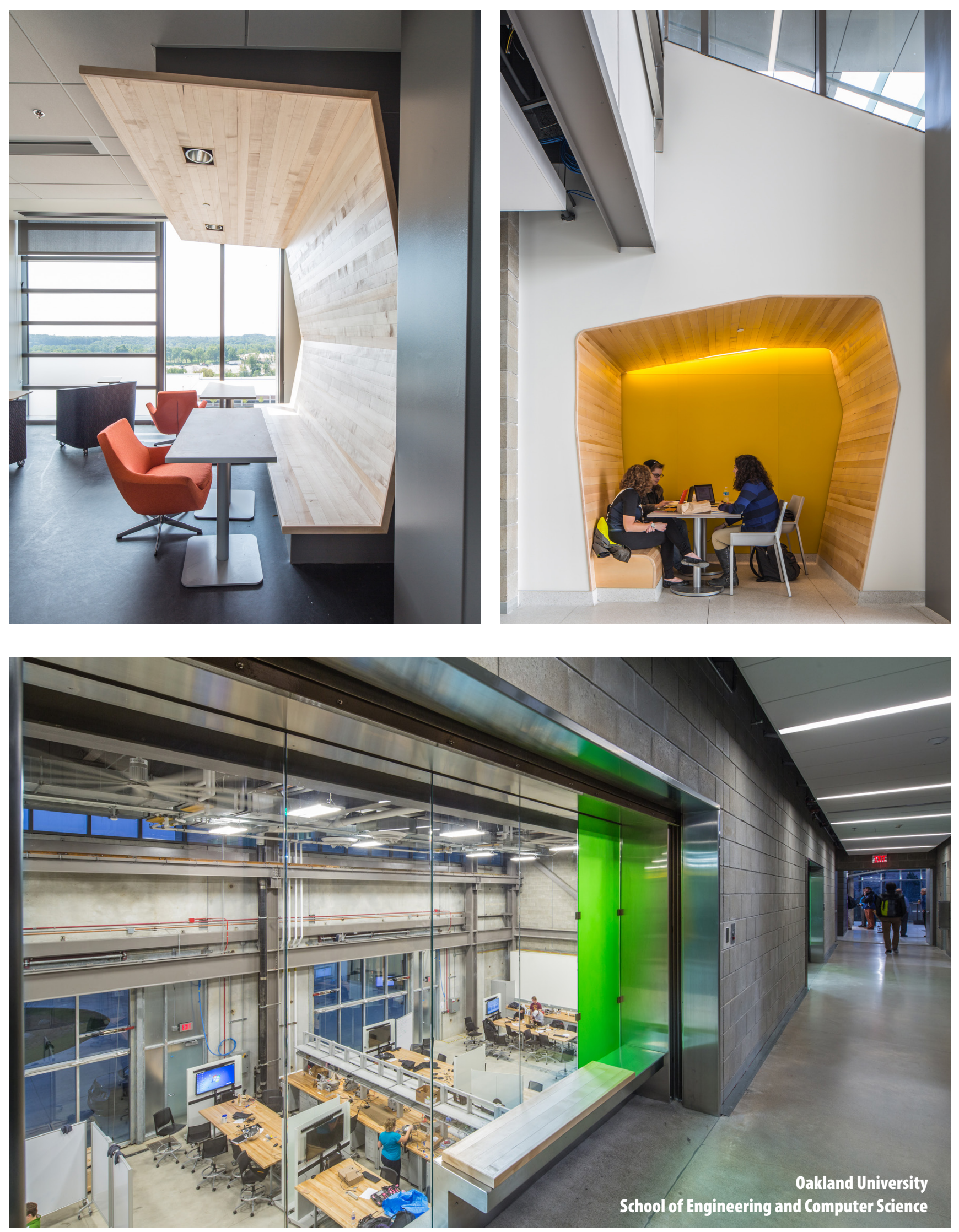
With more than 134,000 gross square feet of space, the cutting-edge facility includes hands-on, team-based learning spaces to support a variety of interdisciplinary projects; an assortment of collaborative spaces that students can easily reconfigure; and exposed structure and building systems that show students how the building fits together and functions.

More specifically, a high-bay capstone lab positioned front-and-center on the first floor features a glass ceiling putting science on display from above. A rooftop energy lab includes a dashboard allowing students to assess how the building's advanced energy system is functioning. They can conduct experiments on solar and wind generation in response to weather variables, monitor energy usage, and even propose improvements to the operation sequence.

The building also includes side-by-side sophomore and senior labs that express similar concepts on different scales: sophomores designing a small, desktop robot, for example, may easily consult or partner with seniors building a larger, walking robot.

The lobby, meanwhile, acts as a student demonstration space, and corridor windows throughout offer clear views into project labs. Even the building's location and orientation on campus were selected to encourage non-engineers to enter and interact, and to help establish engineering as a gateway and hub for students campus-wide.

To reinforce this commitment to peer-to-peer education and active, engaged, studentled learning, informal learning spaces were incorporated on all five floors - including nearly 30 percent of the second floor's area. Such spaces vary widely by size, capacity, level of enclosure, adjacency to main corridors, and flexibility/mobility, accommodating many potential uses.

In order to assess the occupancy and use of these informal spaces, and thus develop a measure of student engagement within the building, SmithGroupJJR conducted a study in late 2016. ${ }^{11}$ After observing 25 possible collaboration spaces over two weeks and a total of 90 hours, the studies revealed the following conclusions: 1) informal learning spaces located near main circulation paths saw roughly twice the interaction level of those farther away (meaning more dialogue, less reading/laptop use); 2) spaces with a novelty artistic expression were used 85 percent more than those without; 3 ) spaces with tables and fixed furniture saw both more use and interaction; 4) spaces providing technological support encouraged greater levels of interaction; and 5) smaller spaces (for two to five students) were used more, but with less interactivity than larger spaces.

These findings point the way toward designing even greater levels of interactivity and peer-to-peer learning into future projects.

\section{Conclusions and Future Research Needs}

The concepts and best practices outlined in this paper are neither proprietary to SmithGroupJJR, nor, in many cases, unique to engineering. In fact, many of the ideas are applicable, even in-demand, across a wide swath of higher education. Collectively they signal evolving attitudes toward long-accepted tenets of higher education in a highly competitive academic and professional environment. 
More specifically, they represent an ongoing shift from the didactic, one-way model of the past toward one that encourages more fluid interactions among students, faculty, and industry representatives both within and across disciplines.

As a field, engineering is uniquely positioned to both embrace and benefit from these changes due to its inherent disciplinary breadth and technical depth. Emphasizing values of engagement, cooperation, experimentation, and innovation at the earliest levels of engineering education are not simply about attracting and retaining students at individual schools, but rather about moving forward the field as a whole.

As this paper demonstrates, architecture and design have a critical role to play in this evolution. As higher education institutions look into the future of what is next for engineering education, architects also explore future possibilities. We ask ourselves, what if learning spaces transition to be embedded within industry? What if first-year instruction kicks off with a research project? What if the engineering laboratory is placed within a nursing school? Throughout these potential changes, we will continue to evaluate the success and performance of the learning environments to ensure their design is helping to achieve specific, desired outcomes.

\section{Citations}

1 Yoder, B.L. (2016). Engineering by the Numbers. American Society for Engineering Education.

2 Auburn University. Samuel Ginn College of Engineering [website]. Available: http://eng.auburn.edu/future/gavin/ [accessed 31 Jan 2017].

3 SmithGroup JJR. (27 Apr 2016). ECE Building Named R\&D Magazine's Laboratory of the Year [press release]. Available: https:// www.ece.illinois.edu/newsroom/article/16479 [accessed 31 Jan 2017].

${ }^{4}$ Duke University. Duke Smart Home Program [website]. Available: http://smarthome.duke.edu/ [accessed 31 Jan 2017].

5 Barista, D. (2008). Living in a Green Laboratory. Building Design + Construction. Available: https://www.bdcnetwork.com/ living-green-laboratory [accessed 31 Jan 2017].

6 U.S. News and World Report. Best Undergraduate Engineering Programs Rankings [website]. Available: $\underline{\text { http://colleges. }}$ usnews.rankingsandreviews.com/best-colleges/rankings/engineering-doctorate [accessed 31 Jan 2017].

7 Dickinson M. (6 Oct 2014). ECE Illinois Opens Electrical and Computer Engineering Building [press release]. Available: https:// www.ece.illinois.edu/newsroom/article/9602 [accessed 31 Jan 2017].

8 SmithGroupJJR. Designing for the T-Shaped Student [website]. Available: http://www.smithgroupjjr.com/design_topics/ designing-for-the-t-shaped-student\#.WJFskBsrJEY [accessed 31 Jan 2017].

9 Oakland University. School of Engineering and Computer Science Homepage [website]. Available: https://oakland.edu/secs/ [accessed 31 Jan 2017].

${ }^{10}$ Oakland University. New Engineering Building [website]. Available: https://oakland.edu/secs/new-engineering-building/ [accessed 31 Jan 2017].

${ }^{11}$ Roberts L., Lee S., et al. (22 Nov 2016). Promoting Peer to Peer Learning. Case Study: Oakland University-Engineering Center [presentation]. 